\title{
Language and Power Relations in Selected Marriage Ceremonies' Songs among the Agĩkũyũ and Akamba Communities of Kenya
}

\author{
J. W. Kinuthia (Corresponding author) \\ Pan Africa Christian University \\ Kenya \\ E-mail: Janeminja2013@gmail.com
}

R. Gachari

Daystar University

Kenya

E-mail: muthonigachari@gmail.com

B. Wambua

Daystar University

Kenya

E-mail: bmwambua15@gmail.com

Received: February 24, 2021

Accepted: March 10, 2021 Published: March 13, 2021

doi:10.5296/ijch.v8i1.18406

URL: https://doi.org/10.5296/ijch.v8i1.18406

\begin{abstract}
The genre of songs is a critical component of marriage discourse among many African communities. Language use in the songs within this premise is a means of conveying messages that enable the participants to express some commonsense assumptions that are implicit in the conventions according to which people interact linguistically. The focus of this paper is to illuminate the connections between language and elements of social life such as
\end{abstract}


gender and power within this social practice and how these may define a society's worldview, articulate societal consciousness, social emancipation and enhancement of social justice. A random sample of marriage ceremony songs from the two communities have been analyzed with a view of discussing how language within this discourse context has been used to give shape and meaning to the world, how language constructions are central in drawing the relationships between language and thought, how we understand abstract meanings and how context influences meaning. The study is grounded on the principles of Wodak and Meyer's (2004) Discourse Historical Approach where expressions in the songs have been qualitatively examined leading to the argument that language is significant in the production and maintenance of social relations of power and this contributes to the shaping of societal understanding, thoughts and feelings, defining people's relationships with each other, establishing the kind of speech that one is involved in as well as describing societal ideologies. The findings of this paper are of benefit to leaders and policy makers in our society who are charged with the responsibility of guiding the development of indigenous knowledge systems for posterity. The general public too as consumers of cultural knowledge would benefit from these insights since they contribute to their understanding of the perceptions and meanings embedded in the songs that they so love to participate in.

Keywords: discourse, language, power relations, marriage ceremonies' songs

\section{Introduction}

According to King'ei (2002), language is an integral part of the human society and thought system and has been observed to influence socio-economic, cultural and political development. It is significant in the production and maintenance of social relations of power thus the need to increase consciousness concerning how its elements contribute to the domination of some people by others (Fairclough, 1989).

For Fasold (1990), when people use language, they perform more than just trying to get others to understand their thoughts and feelings since they use it in subtle ways that enable them to define their relationship to each other, identify themselves as part of a social group, as well as establishing the kind of speech event that they are in. Fairclough (1989) further argues that languages are ideologically powerful and this is experienced through how they function hence the need for those interested in relationships of power in modern society, equally considering it as it articulates consciousness, reflects culture and affects socialization. Catalan and Rose (2005) view language as a means through which people shape their view of society, organize their knowledge, learn new things and assimilate the norms and social patterns of their community.

The units of analysis in this paper involve wedding ceremonies' songs which in this context are considered as a genre since they are a type of communication that is sharing a common communicative purpose. Genres too are known to have structures which according to Swales (1990) respond to cognitive interpretations among the discoursal components of the texts involved. They facilitate the achievement of communicative goals within a discourse community. Analysis of discourse as a form of social interaction examine how people use language to accomplish social acts, such as constructing roles and identities (Van Dijk, 1997). 


\section{MInstitute ${ }_{\text {Int" }}^{\text {Macrothink }}$}

These ends are achieved not only through the content of what is said, what is selected, implied or omitted but also through the structure and patterning of talk which in this case refer to the structure and content of the songs.

The Gĩkũyũ marriage negotiation process is a discursive space where language plays a critical role. Participants in this discourse practice must therefore recognize the power of language and its potentialities as a negotiating instrument. An understanding of the creative power of language requires that the user comprehends how language elements shape people's thoughts as well as contributing to the relationships and situations in which they negotiate with others. Evidently, Gĩkũyũ marriage negotiation constitutes of language and is a set of social behaviors enacted within the domain of language (Kinuthia \& Mutiti, 2017). Moreover, relations of power enhances sustainability of cultural values in human groups that appropriates the legality of the marriage union. The discursive domain is defined by a five stage process which involves the parents of the groom making numerous visits to the bride's home during the negotiation and payment of bride price. Song and dance play a major role during the process and is often used as a negotiating instrument. For instance, songs are used as a method of announcing arrival of the groom's party into a bride's parent's home and also when the two parties agree, they celebrate the success of their negotiation through the same. Through them, identities, roles and power associated with femininity and masculinity in society together with social constructions which are easily identifiable through names and naming, expressions that are verbal or non-verbal as well interpersonal interactions, are communicated.

\section{Materials and Methods}

The data for this paper is a random sample of 10 marriage songs from the Agĩkũyũ and Akamba communities. Data was collected during live negotiation ceremonies and thus this discourse component is a part of a major research project. The songs were translated and transcribed, then information coded according to the themes identified. The data was then qualitatively analyzed as per those themes.

The language elements considered were the verbal, non-verbal and other extra linguistic aspects in the songs where the analysis process factored in, the use of unequal relations of power and explained how they are established and maintained: through grammatical terms as well as a person's control of the social occasion. Inferential meanings were drawn through the use of available knowledge of the historical background in which these social acts are embedded.

\section{Theoretical Framework}

The analysis of songs in this paper is guided by Wodak and Meyer's (2004) Discourse Historical Approach (DHA). Analysis of the data collected was in terms of the relationship between language and other elements of social practice and events. DHA is a framework that evolved out of Critical discourse analysis (CDA) and therefore is fore grounded in its tenets. In investigating historical, organizational and political texts, the Discourse Historical Approach (DHA) attempts to integrate a large quantity of available knowledge about the 
historical sources and the background of the social and political fields in which the discursive 'events 'are embedded; a view that is central to this paper since data is derived from texts which arise out of a customary practice.

The approach also analyzes the historical dimension of discursive actions and explores how particular genres of discourse are subject to diachronic change. For the DHA approach, language is not powerful on its own but is a means to gain and maintain power depending on the use powerful people make of it. Power is discursively exerted not only by grammatical terms but also by a person's control of the social occasion. DHA also considers inter-textual and inter-discursive relationships between utterances, texts, genres and discourses as well as extra linguistic social variables, historical organization and situational frames (Wodak \& Meyer, 2004). The approach has been described as an interdisciplinary and problem oriented approach which analyses discursive practices by oscillating between theory and empirical data. It focuses on social problems and especially on the role of discourse in the production and reproduction of power abuse or domination by taking the experiences and opinions of members of such groups and supporting their struggle against inequality (Van Dijk, 1997).He further argues that the complex 'real world problems' that CDA deals with also need a historical, cultural, socio-economic, philosophical, logical or neurological approach, depending on what one wants to know hence, this paper's use of Discourse Historical Approach tenets in its analysis such as the power of language to shape perceptions, ideologies and identities.

\section{Discussions}

Language is a common social behavior which can bring out relations of power and domination. According to Fairclough (1989), there are conventions that define how people interact linguistically at times even without conscious effort. Many times, the inherent meanings of such interactions are assumed though embedded in language. The context in which it is used are ideological underpinnings that enable users to produce and maintain utterances which have implications of power relations as can be seen in the analysis of the songs in this paper.

\subsection{Language and Identity}

Language can be used to construct personal identities. This happens through names, naming practices and rituals together with systems of address. These aspects are central to this paper because address systems are culturally determined for example when they are used to help establish identity within a context. A good example is song 1 below which is a popular Gĩkũyũ wedding song where the groom's mother is addressed in a traditionally accepted respectful manner (mother so and so). The bride too is addressed in a manner that suggests one who is delicate or tender hence the metaphor of 'infant'. Her mother-in-law to be, is being invited to receive her while still being cautioned to take care of her new daughter-in-law as she is just 'like an infant'.

\section{'Nyina wa Kamau tonya thini woe gakenge' (soloist)}

(Mother Kamau, come inside ((the house)) and pick up the infant) 
Mwana ndanyitagwo na njara ya umotho anyitagwo na ya urio tonya thiini woe gakenge (all)

(A child is held ((meaning protected)) with the right hand and not the left, come in and pick up the infant)

\section{Song 1}

In this context, culture determines the degree of formality, of intimacy and of relative relationship status of the participants involved in the interaction which in this case is the groom's and bride's parties. The song is usually sung by the bride's party when allowing the groom's party to pick up their bride. In this social context, disregard of the rules can lead to some form of disapproval or sanctions or at worst be interpreted as an insult. Referring to the groom's mother as "mother Kamau" is an example of using a naming system to express an attitude, in this case, respect, or as a signal of recognizing the groom's mother's status. This is especially so if repeatedly used (Thomas, et.al. 2004).

It is also important to note that names are culturally determined as a way of establishing identity within a context. In song 1 above for instance, no one else can be called upon to come and receive the bride except the groom's mother. She must be addressed using the name of the groom (even if she normally is addressed using other names of her children) as a way of demonstrating that within this context, Kamau (who is the groom), is the main character. Addressing her thus signals respect while at the same time is a subtle way of telling her to take care of their daughter who is being given to her son hence the holding (protecting) her "with the right hand and not the left". This is further intensified through the metaphor of a 'gakenge' meaning an infant. It inherently means that the bride is delicate and requires proper care and needs to be valued just like a new born baby. The use of this metaphor also signals the closeness of the relationship between a parent and a child while the power embedded in language use is demonstrated through the fact that in this context, the song can only be conducted by the bride's side since they are in control of this social event; at least for now. Such language use acts as a means of legitimizing existing social relations through the appearance of ordinary familiar ways of behaving which take these relations and power differences for granted most of the times (Fairclough, 1989).

Language being an important aspect in the construction of individual and social identities can be a powerful means of exercising social control. Being a member of a particular group or community often means adopting the linguistic conventions of that group, not just in relation to words use but also in relation to the way you see them. The way those conventions are defined and maintained is usually "controlled by the group rather than the individual" (Thomas et.al. 2004, p.158). Within the genre of songs and in this context the marriage songs, women are the ones who control the singing and depending on the stage at which the ceremony is in, either the bride's or the groom's side may be in-charge. For instance as seen in song 1 above, before the bride is handed over, her people demonstrate their power through conducting the singing and the content of their songs while after the groom's side receive their bride, they may express the success of their efforts in a song like the Gĩkũyũ one below:

Mwana ni mwega atumaga thiore githioro... (Soloist) 
(A child is so precious, they will make you ((parent)) go round bends...)

Mwana ni mwega atumaga thiore githioro... (All repeat)

\section{Song 2}

The song is usually sang by the groom's party after they have been allowed to carry the bride. This context demonstrates the power of discourse as people try to negotiate for power and dominance. According to song 2 above, serving the needs of a child could involve a lot of hardships as signaled by "going around bends" but the singers show that parents always consider doing it for the benefit of a child as always joyous. Language use in this context is presented as a phenomena that is constantly build and negotiated as we interact with people and they are multifaceted since people switch into different roles at different times as they exercise social control (Thomas, et.al. 2004).

\subsection{Language and Ideology}

Fairclough (1989) also contends that the exercise of power in modern society is increasingly achieved through the ideological workings of language and therefore language is important enough to merit the attention of all citizens. He observes that ideologies are closely linked to power, because the nature of the ideological assumptions embedded in particular conventions, depends on the power relations that underlie that convention. For example as brought out through song 1 above, the bride's family, due to the historical organization of the discourse practice in this context has power so long as the bride is with them. That is why they have the power to advise the groom's mother regarding how she needs to handle their daughter: 'with the right hand and not the left one'. This perspective clearly demonstrates Foucault's (1977) argument that power is a practice that is exercised within a relational network. This view is further emphasized through song 3 below:

Hodi karibu, kwa nyina wa Kagure hodi karibu (soloist from the groom's party)

Knock knock, may we come into Kagure's mother's house, may we come in?

\section{Mugucereirwo ku hodi karibu? (Response from the bride's party)}

Why have you come so late?

\section{Song 3}

This song is usually started off by a groom's party as they seek for permission to be allowed into a bride's parents' home. The groom's and bride's party use the song to negotiate under what terms the groom's party is to be allowed in. Should there be any items or fine demanded by the bride's party since ideologically the social occasion gives them more power at this stage, the same are to be exchanged and determined as the two parties interact linguistically through the song. For instance, a response (as in song 3 above) demanding for an explanation for coming late inherently tells the groom's party that they are not simply going to be allowed in. They are to interpret the demands of their hosts at times with the aid of non-linguistic variables such as gestures. This clearly demonstrates Fairclough's (1989) view that ideologies are associated to power, and that it depends on the nature of the ideological assumptions and 


\title{
Macrothink
}

how they are embedded into particular conventions since this determines the power relations implied.

\subsection{Language and Context}

Power is a phenomenon brought into play through discourse which "must be firmly located in the systematic examination of features integral to the discourse itself" (Watson, 1990, p.280).For instance, in the Kamba song below, one role of the bride is 'fetcher of firewood'. Through such language use, gender roles and other societal worldviews are articulated.

Mutiswa! Mutiswa has 'gone up".

Fetchers of firewood have increased

The community has grown. Mambwa has slept. The community ((of young unmarried women)) is now one less

\section{Song 4}

Hutchby (1996) further argues that power can be addressed as a phenomenon that is both highly specific and also diffusely and pervasively present within an interaction. According to the next Kamba song (song 5 below), being married has power to define what society expects of specifically those that are married.

\author{
Mwania, you are now married \\ You should know you are now an elder \\ Forget your old companions. Stop going to the dances you went to \\ Stop going to the movies like you did before \\ Mwikali, Mwikali is married, know that you are now a wife \\ Leave your former friends \\ Forget the dances you used to attend \\ Know that you are now a wife
}

\section{Song 5}

As can be observed, society expects that marriage brings about change of behavior such as 'stop going to dances' which might suggest a life of irresponsibility and adopt one of responsibility '...now you are an elder'. This usage underscores the relationship between how language is used and other elements of social practice such as enhancement of social justice, in this case the new responsibility that comes with marriage. As Foucault (1977) would argue, discourse give shape and meaning to the world and our relationships in it which is founded on the premise that power operates in the most mundane contexts of everyday life such as marriage. Furthermore, language users recognize and attempt to forestall the effects of the powerful strategies used by the host (consider song 3) or they may resist by attempting to adopt the powerful strategies available to the host, for themselves (Hutchby, 1996). Thus, 
power is seen in the relationships between turns as the two sides engage in a duel through the exchanges in the song (consider song 1). Thus, the influences on meaning arising from deconstruction of linguistic items make it possible to create contextual meaning.

\subsection{Language Use and Perception}

Thomas et.al (2004) has observed that how we talk and how we perceive ideas and concepts are linked. In human society, there is a lot of evidence of the exploitation of the links between language use and perceptions.

Language constructions such as figures of speech make significant constraint on interpretation processes. Katz et al (1998) argue that an understanding of the processing of figurative language is central to several important issues such as relationship of language and thought, how we process language and how we comprehend abstract meanings. Important issues to consider are what figures of speech tell us about the structure and conceptual system in language use, why people choose to speak metaphorically, the role of culture and social factors in comprehending figurative language and why language users choose to be figurative language users. In song 1, the metaphor of an infant enables us to see how society views a bride: precious, delicate, variable, among others.

In song 6 below, the metaphor of not taking issues pertaining to children as jokes is an admonition to society to take care of their children. This way, the value placed on children by society is underscored. Since this song is common during dowry payment, it signifies that when one does not treat a child as a joke, they are usually rewarded by receiving gifts when the said children get married. In this context too 'mwana' the child being referred to is the girl child and society is expected to process this meaning as such.

\section{((...Mwana ii mwana ndekwenda itheru, mwana ndekwenda mitheko))}

A child, a child, should not be taken lightly, a child should not to be treated as a joke

\section{Song 6}

Language users in this context should bear in mind that metaphors are comparisons where meanings are derived from a sharing of features for instance the phrase 'ndekwenda mitheko' literally means 'does not need laughter' which does not make sense. In this context therefore, the language user must interpret it as much more: either to mean a child brings joy if brought up well or bringing up a child is a serious business. Thus, comprehending the meaning of the metaphorical usage will require some cultural knowledge in such a case.

The relevance of a given property to a topic can best be described at the level of dimensions of attribution. According to Katz, et al (1998), the function of a metaphor is to extend human communication and conceptual capacities. Metaphors are windows to the systems of knowledge that are relevant and central in a given culture. They have linguistic identity to events, persons and entities that use already existing systems of knowledge. They are not only the 'dream-works' of language but also of thought and perception. It is thus of critical relevance that language users pay attention to them especially in the context of songs. 
Grammatical constructions can influence an interpretation process so that people may easily infer the figurative meaning of a particular word or phrase. Non-literal language is used in a non-dominant (unfamiliar) way. A lot of figurative language is based on learned conventions (Katz et al's, 1998). For instance, to unravel the meaning of the language items "protect with the right hand and not the left "in song 1 above, can only be arrived at by paying attention to the words and the syntax of the expression. In Katz et al's (1998) view, context will influence contextual or literal meaning. In principle, the context might engage one or more conceptual metaphors which in turn might have a role in comprehension. In a sense, non-literal meaning in unfamiliar proverbs is generated when there is sufficient contextual support for that sense. In this case, the right hand is normally associated with strength and positivity hence the exhortation to use it in the protection of the child instead of the left one.

A further insight into the understanding of the role of metaphors in interpretation of meaning is seen in the way a speaker can frame what he or she wants to say in order for the comprehender (at least the audience in the know) to appreciate the difference between the expressed literal and the intended non-literal meanings. For example, in song 7 below, the intended message which is to make people stand and dance is more expressly brought out through an expression that seems to be simply talking about a musical instrument. Consider the song below:

Iiriri kinanda iiriri kinanda, kinanda ni kiguchio (soloist)

\section{Ii ii iiriri kinanda (all)}

(Hail the guitar, string it, play it ooh the guitar!

Ooh ooh the gutar!)

\section{Song 7}

This way, the intended meaning is perceived in a clearer way than just a literal paraphrase of the intended meaning which is to call people to dance and celebrate the groom and the bride. This same perspective is evidenced by the Kamba song below:

\section{Tingilingiliii, tingingili, atui umaì \\ Mwone, tingilingili \\ (Bells ring, bells ring, neighbors \\ Come see, bells ring)}

\section{Song 8}

According to Jaszczolt and Turner (2003), there are two ways of using literal and figurative language. Literal language refers to words that do not deviate from their defined meaning while nonliteral or figurative language refers to words or expressions that exaggerate the usual meanings of the component words. Figurative phrases provide linguistic evidence of conceptualization. In this analysis the usage of language in song 1 is non-literal while that of song 7 and 8 are literal. Some people argue in favor of language as an encoder of culture such 
that language users require the knowledge of the cultural system in addition to knowledge of the linguistic system. In the Kikamba song (9) below, an understanding of the "celebration" to mean a wedding celebration requires context as well as the content.

Kyathi kya suoo ni uathimo

Kyathi kya suoo ni uathimo

((Celebration today is a blessing

Celebration today is a blessing))

\section{Song 9}

The analysis further provides evidence that such concepts are dependent on culture as well as knowledge as emphasized through Wodak and Meyer's (2004) observation that such an analysis would demonstrate the role of analyzing discourse so as to demystify and decipher societal ideologies that are embedded in language.

The process of using non verbals involves sending or receiving wordless (mostly visual) cues. It encompasses body language, paralanguage, proxemics and haptics among others. Culture plays an important role in nonverbal communication since it does not only influence interpersonal interactions but also convey cultural values. Such a perspective is illustrated by the Kikamba wedding song below:

\section{Ala makulasya, ala makulasya \\ Athoni makauma va, tyaya tyaya}

\section{Athoni-iii tyaya tyaya mũyũkei mũmone}

((Those who were asking, those who were asking, in-laws where are you coming from?

Here, here, in-laws-s-s, here here come see them))

\section{Song 10}

The song suggests that the bride's parents had looked forward to their daughter's wedding and by use of the long sounds and non-verbal dramatics that would accompany the expression "here, here, come and see", they are able to taunt those who may have despised them as they also express their joy. The song demonstrates how people use non-verbal elements unconsciously sometimes as signals and the mediation of space. Wrong messages can be established if the body language conveyed does not match the verbal message (Jaszczolt \& Turner, 2003). When absorbing a non-verbal message, people focus on the entire environment around them meaning that they are using all their five senses. The extraction of meaning from a verbal or nonverbal act has to do with discovering the motivation behind that act. It is important to note that interpretations of nonverbal sometimes have dependent variables such as age, cultural diversity, cognitive and interpretation functions among others. According to Key (1977), verbal and nonverbal expressions of status (reflecting the economic system) and male/female differences are the most important features of differentiation in the dynamics of 
human interaction. Thus, language use is a critical component of communicating societal perceptions.

\section{Conclusion}

Given the fundamental nature of song as a genre, their analysis in this paper provide an opportunity for accounting for structures, strategies and functions of the song texts. The analysis too concerns itself with how usage helps in establishing and maintaining power relations among participants from both the groom's and bride's parties. Meanings in wedding songs are culturally determined and each language aspect is important in the construction of identities, ideologies and perspectives regarding marriage in the given society. The analysis of the wedding ceremonies' songs in this paper seem to clearly demonstrate a view anchored on Schifrin's (1994) observation that language creates and is created by social context and so social action does not only display knowledge but is also critical to knowledge. Thus, the grammatical structures, figurative expressions and nonverbal cues are dependent on culture and can only be deciphered and demystified through use of cultural knowledge. Only then do the actions of the participants and the social circumstances that they are operating in, become intelligible. It is therefore the contention of this paper that songs are an important form of communication comprising of language aspects that are useful in socio-cultural undertakings and that they lead to an understanding of a society's value system.

\section{Acknowledgement}

The authors are very grateful to our respondents who took their time to provide adequate information for this paper. Without your input, coming up with this article would not have been possible. We truly appreciate you.

\section{References}

Catalan, J., \& Rose, M. (2005). Inking Gender and Second Language Education, Cited in Ikaria-Maina. N. (2013) Linguistic Sexism: A Case of Gikuyu Language Discourse. International Journal of Science and Research (IJSR).

Fairclough, N. (1989). Language and Power. London: Longman Group.

Fasold, R. (1990). The Sociolinguistics of Language. Oxford: Blackwell Publishers Ltd.

Foucault, M. (1977). Power/ Knowledge. Hermel, Hempstead: Wheatsheaf. Harvester. Retrieved from http://library.queensu.ca/ojs/index.php/surveillance-and-society/article/download/4155/4158

Hutchby, I. (1996). Confrontation talk: Arguments, Asymmetries and Power on talk radio. Mahwah, New Jersey: Lawrence Erlbarm publishers.

Jaszczolt, K. M., \& Turner, K. (2003). Meaning through Language Contrast (Vol. 2). Amsterdam: John Benjamins. https://doi.org/10.1075/pbns.99

Katz, A. N., Raymond, W. G., \& Turner, M. (1998). Figurative Language and Thought. New York: Oxford University Press 
Key, M. R. (Eds.). (1977). The Relationship of verbal and nonverbal communication. Illinois, USA: Lake Forest.

King'ei, K. (2002). The Role of African Languages in Development in the $21^{\text {st }}$ Century: Reflections on Policies on African Languages in Education. Nairobi: Chemchemi, 2(1). Retrieved from http://etdlibrary.ku.ac.ke/bitstream/handle/123456789/12669/The\%2520role\%25

Kinuthia, J. W., \& Mutiti, Y. J. K. (2017). The Role of Language in Creating and Sustaining Power Differentials in Gikuyu Marriage Negotiation Discourse. RUWAZA AFRIkA, Journal of Contemporary Research in Humanities \& Social Sciences, 37-51. Retrieved from http://www.ruwazafrika.com/index.php/2017-02-27-06-31-45/ruwaza-journal-fifth-edition

Schiffrin, D. (1994). Approaches to Discourse. Cambridge: Blackwell.

Swales, J. (1990). Genre Analysis: English in Academic and Research Settings. Cambridge: Cambridge University Press.

Thomas, L., Wareing, S., Singh, I., Peccei, J. S., Thornborrow, J., \& Jones, J. (2004). Language, Society and Power: An Introduction. London: Routeledge. https://doi.org/10.4324/9780203426968

Turner, D. (1990). Gender and Discourse Coherence. Oxford, England: oxford University press.

Van Dijk, T. A. (Ed.). (1997). Discourse Studies: A Multidisplinary Approach. London, England: Sage Publications.

Watson, D. R. (1990). Some features of the elicitation of confessions in murder interrogations. In G. Psathas (Eds.), Interaction Competence (pp. 263-295). Washington DC, USA: University Press of America.

Wodak, R., \& Meyer, M. (2004). Methods in Critical Discourse Analysis. Thousand Oaks, CA: Sage Publications.

\section{Copyrights}

Copyright for this article is retained by the author(s), with first publication rights granted to the journal.

This is an open-access article distributed under the terms and conditions of the Creative Commons Attribution license (http://creativecommons.org/licenses/by/4.0/) 